Results Economic factor is inherent in the sex work initiation and FSW migration. Families (mainly mother in the family) are playing a prominent role in the decision regarding the initiation, migration, selection of destinations, brothel madams, financial dealings and the contract agreement with brothel madams. Peer influence, economic status of a family and established contacts with destinations are supportive factors for FSW migration. Migrant sex workers are made to believe that they have the responsibility of fulfilling families' economic needs including the repayment of loans.

Conclusions Information on role of a decision maker in the lives of migrant sex workers can be used to decide regarding resource allocation and programmatic prioritisation. Building strong rapport with families and linking the place of origin and destination may increase the ability to reach FSWs at an early stage of sex work profession.

\section{P2-S2.03 REACHING THE NEW AND YOUNG MIGRANT SEX WORKERS: STRATEGIES FOR INTERVENTION}

\section{doi:10.1136/sextrans-2011-050108.299}

${ }^{1} \mathrm{~S}$ Ramanaik, ${ }^{1} \mathrm{M}$ Doddamane, ${ }^{1} \mathrm{~S}$ Srikantamurthy, ${ }^{1} \mathrm{I}$ Ravindra, ${ }^{1} \mathrm{R}$ Meti, ${ }^{1} \mathrm{~T}$ Hiremath, ${ }^{1} \mathrm{~A}$ Mirji, ${ }^{1} \mathrm{G}$ Holidasar, ${ }^{1} \mathrm{M}$ Pudur, ${ }^{1} \mathrm{~T}$ Ragavendra, ${ }^{1} \mathrm{P}$ Bhattacharjee. ${ }^{1}$ Karnataka Health Promotion Trust, Bangalore, India

Background Large numbers of young girls enter sex work are migrating from source villages in North Karnataka to the brothels in destination cities in Maharashtra facilitated by families, brothel madams and network operators in a very confidential way. Though there is strong evidence that girls from the North Karnataka region start sex work at the age of 15 and are not reached adequately by traditional targeted intervention programmes in either source or destinations. New and young sex worker (FSW) are particularly vulnerable to HIV as they have higher clients, work under power structures where condom negotiation or access to services is poor and do not possess skills to negotiate condoms with clients. Evidence from Integrated Behaviour and Biological Survey in Karnataka show the HIV infection among young FSWs is $28.3 \%$ and $16.7 \%$ in 2009 and 09 respectively and even it is very high (38.5\% \& 35.6\%) with the women enter through traditional devadasi system.
Methods The project is providing workable strategies to work with new and young migrant FSWs who are one of the crucial links in HIV prevention. A team of migration counsellors (MCs) tracking and connecting them to the organizations working at source and destination to ensure, they have access to condoms and services. Providing pre-departure and post-arrival counselling, connecting family at source and the free helpline services is also made available. Intervention with brothel madams and family member is an advantage to reach early. The project also working with adolescent girls in traditional devadasi community by developing their life skills to ensure that they are aware of HIV prevention methods and have skills to negotiate their use if and before they enter sex work.

Results In 1-year period, 1200 young and new migrant FSWs are registered and availing services at both the places. MCs are regularly visiting destinations and able to track $90 \%$ of migrant FSWs on every month. 7500 pre departure and post arrival counselling sessions were conducted and all the families at source are contacting regularly. 223 brothel madams are identified and all are actively involved in the program. 1464 adolescent girls are enrolled for life skill education program at source villages.

Conclusions Young and adolescents' preference for brothel-based sex work suggests the need for programmatic focus on brothel madams, family members and adolescents program at source as an effective way to reach these young FSWs

\section{P2-S2.04 SEX WORKERS, MOBILITY AND MIGRANT LATINO MEN IN THE US SOUTH: FINDINGS FROM AN EXPLORATORY RAPID ETHNOGRAPHIC ASSESSMENT IN NORTH CAROLINA}

doi:10.1136/sextrans-2011-050108.300

${ }^{1} \mathrm{~K}$ Kroeger, ${ }^{1} \mathrm{~T}$ Sangaramoorthy, ${ }^{1} \mathrm{P}$ Vallila-Buchman, ${ }^{1} \mathrm{R}$ Robitz, ${ }^{2} \mathrm{P}$ Moore, ${ }^{2} \mathrm{~J}$ Clymore. ${ }^{1}$ Centers for Disease Control and Prevention, Atlanta, USA; ${ }^{2}$ North Carolina Department of Public Health, USA

Background A growing number of studies indicate frequent use of female sex workers among migrant Latino men in the US South, yet little is known about the context in which sex workers and clients

Abstract P2-S2.03 Figure 1 Logic Model to Reach New \& Young FWS. 